\title{
Mariluz Escribano, historia de una Maestra (cuando la ausencia es un dolor y una bandera)'
}

\author{
Mariluz Escribano, History of a Mentor \\ (When absence is a pain and a flag) \\ REMEDIOS SÁNCHEZ GARCÍA \\ Universidad de Granada \\ España \\ reme@ugr.es
}

(Recibido: 5/I2/2OI9; aceptado: 8/I2/20I9)

Resumen. En el presente ensayo, escrito con voluntad literaria, se hace un recorrido por la trayectoria literaria y biográfica de Mariluz Escribano Pueo (1935-2019), una de las voces esenciales de la poesía española contemporánea que, durante demasiados años, ha permanecido silenciada. A través de sus propios versos se analiza su trayectoria vital y los hitos que fueron construyendo a una docente ejemplar, que ha sido también uno de los pilares del Departamento de Didáctica de la Lengua y la Literatura de la Universidad de Granada desde su fundación.

Palabras clave: poesía española; educación literaria; compromiso docente; Mariluz Escribano Pueo; siglo XX.
Abstract. With this essay, written with literary intentionality, we make a journey is made through the literary and biographical career of Mariluz Escribano Pueo (19352019), one of the essential voices of contemporary spanish poetry that, for too many years, has remained silenced. Through own verses, analyzes her vital career and the milestones that were building an exemplary teacher, who has also been one of the mainstays of the Department of Didactics of Language and Literature of the University of Granada since its foundation.

Keywords: Spanich poetry; literary education; teaching commitment; Mariluz Escribano Pueo; XX century.

\footnotetext{
${ }^{\text {I }}$ Para citar este artículo: Sánchez García, Remedios (2O2O). Mariluz Escribano, historia de una Maestra (cuando la ausencia es un dolor y una bandera). Alabe 21. [www.revistaalabe.com] 

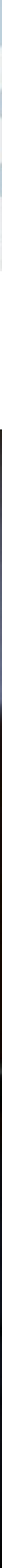

Autor de la foto: Ramón L. Pérez

\author{
¿Murió?... Sólo sabemos \\ que se nos fue por una senda clara, \\ diciéndonos: Hacedme
}

un duelo de labores y esperanzas.

“A Don Francisco Giner de los Ríos", Antonio Machado 


\section{I.- Prefacio. Porque se fue la maestra....}

Es la palabra "maestra" un vocablo cargado de significados hondos, de verdades de infancia y de luz que abrasa cuando el tiempo pasa y las noches se hacen más frías. $\mathrm{Y}$ ahora, tal que hace unos meses, el veinte de julio se nos fue una Maestra, de las de sonrisa paciente y manos capaces de construir un universo con esas monedillas de oro que son las palabras. Se llamaba Mariluz Escribano Pueo y todo el mundo ha ido conociéndola en los últimos años como la gran poeta de la memoria y de la concordia civil, un referente literario inexcusable de la poesía de los últimos treinta años que ha tenido al final de su vida el reconocimiento que durante demasiados años se le hurtó. Premio Andalucía de la Crítica por su poemario Umbrales de otoño (2OI4), Medalla de Oro al Mérito de la Ciudad de Granada, Bandera de Andalucía, Premio Elio Antonio de Nebrija de las Letras, Mariluz Escribano es un ejemplo de esfuerzo, de lucha, de superación, de humanidad y de compromiso. Pero es muchas cosas más, esencialmente, una maestra en el sentido más amplio del término, trascendida su acepción de 'Persona que enseña una ciencia, arte u oficio, o tiene título para hacerlo'; ella resulta, en lo que a mí respecta, una fuerza de la naturaleza capaz de cambiar el curso de las circunstancias. Catedrática de Didáctica de la Lengua y la Literatura de la Universidad de Granada, yo nunca tuve la fortuna de que me diera clases en sus cuarenta años como docente. Pero, aunque no fuera mi profesora, es mi maestra y lo digo en presente, desde la conciencia de que lo que soy, mi forma de estar en el mundo, a ella se la debo y nunca he de olvidarlo. Porque maestro no es quien imparte clases en cualquier nivel educativo, ya lo he dicho; es algo infinitamente más trascendente en mi opinión. Maestro es ser referente ético, modelo de vida para las generaciones que vienen y se miran en sus ojos, buscando respuestas a verdades hondas con voluntad de amparo. Los niños, y también los estudiantes universitarios, para Mariluz, no eran vasijas que se llenaban de conocimiento, de ciencia lingüística o teoría literaria, sino luces que se encienden y que son madrugadas de esperanza, mano tendida a ese conocimiento que fortalece, a la alegría de saber y saberse. Porque aprendemos, leemos y estudiamos para conocer el mundo pero, esencialmente, para conocernos a nosotros mismos en última instancia y casi sin darnos cuenta. Para averiguar nuestra identidad más profunda, ésa que nos hace personas irrepetibles a cada uno, con unas capacidades y unas potencialidades que, bien orientadas, nos hacen crecer por dentro y ser útiles a la sociedad. Las personas que nos prestan su mano para hacer ese camino no son los docentes sino los Maestros, seres de excepcional generosidad, dedicación y habilidad que son capaces de extraer lo mejor de nuestra alma y convertirlo en una forma de vida. Y me preocupa mucho, como profesora universitaria, que nos olvidemos de ellos. Que aquellas personas singulares e irrepetibles que nos han hecho lo que somos pasen a los anaqueles del abandono y no se guarde su huella como quien guarda un tesoro, una flor que nunca pierde su perfume entre las manos.

Sucede demasiado en la universidad que una jubilación implica el silenciamiento o el olvido; que la muerte significa el final, la conciencia de que nada queda ya, ni un 
rastro de voz. Eso no va a suceder con Mariluz Escribano, la poeta inmensa de la mano tendida, la Maestra que era libertad docente, esta mujer extraordinaria de los ojos tristes que habían visto demasiadas injusticias y que, por fin, es ahora libre y violeta después de una enfermedad que inmovilizó sus piernas pero que nunca rozó una cabeza que fue siempre prodigio, magia, sorpresa y ternura. Su legado, el que vamos a preservar, es su modo de estar en el mundo y yo lo he observado los últimos diecisiete años con cercanía de discípula y con mirada de hija, testigo privilegiada de sus últimos años en la Facultad de Educación, de sus clases magistrales a las que me permitió asistir o, incluso, de cómo hacía los exámenes o atendía en las tutorías los problemas cotidianos de estas nuevas generaciones ahogadas entre miles de trabajos para una misma asignatura y papeleo inútil. Aprender, evidentemente y desde su magisterio limpio, para mí no obliga a tales servidumbres. Eso también lo ha sabido hacer Mariluz: crear escuela, mantener su presencia ya jubilada sabiéndose admirada, querida y respetada. Exactamente lo que merece una Maestra con mayúsculas es lo que ha tenido y lo que va a seguir teniendo.

Y puesto que ya no está mirando desde las ventanas de su casa que dan al jardín ni puedo empujar su silla de ruedas camino del Aula Magna donde, como cada año, esta primavera la esperarían trescientos estudiantes en el Festival Internacional de Poesía para que ella se los guardase entre el corazón y el bolsillo, toca ahora proteger lo que ella representa, contar su historia para que no se olvide nada y hacerle un duelo machadiano de labores y esperanzas en el que la educación, formar personas completas y complejas, sea el eje. El magisterio, siempre me decía, es un sacerdocio laico. Efectivamente: es una tarea que implica una dedicación plena y sin horarios que constriñan, un entusiasmo absoluto por transmitir verdades insondables, las ganas de ser parte de la trasformación del mundo al estilo de lo que preconizaba la Institución Libre de Enseñanza, en cuyas ideas ella se formó a través de su madre y, nosotros, gracias a ella en un ciclo que no se interrumpe. Y aquí está su historia, "una historia que no fue infancia alegre, / sino aquello que no pude contar" (GM), escrita al hilo de su poesía en el tiempo, ése que ella me contó, o que tuve el privilegio de compartir y que añoro ahora que ha llegado el frío, porque hay huecos que la vida jamás podrá llenar.

Ésta que sigue es la vida de una poeta, de una docente, de una activista ciudadana, de una mujer infinita y poliédrica adelantada a su tiempo con una riqueza de ruiseñor en los labios que cualquiera que ame la lectura o la docencia debe conocer. De una Maestra con mayúsculas sobre la que nunca ha de caer ese olvido que es nieve porque la llama que Mariluz Escribano ha dejado encendida en nuestras almas y en nuestra forma de concebir la docencia comprometida es tan extraordinaria, que jamás ha de extinguirse porque nosotros seguiremos avivando por siempre su fuego. 


\section{2.- La luz que enciende la mañana ("6n un tiempo de cunas/ mecidas por el viento de la guerra", UO)}

Granada, es jueves I9 de diciembre de I935 y parece que llueve con tímida paciencia la caída de la tarde. Nace la primera niña del matrimonio formado por Luisa Pueo y Costa y Agustín Escribano, ambos profesores de la Escuela Normal de Maestros. Agustín es el Director y, Luisa, la Secretaria de la Residencia de Señoritas Normalistas, una institución al modo de la de Estudiantes de Madrid: con voluntad de propiciar una formación integral para las jóvenes que buscan prepararse para ser mejores. Agustín es un hombre apuesto, leal y sensato que piensa y defiende la educación como herramienta de construcción de la identidad para no someterse a las élites dirigentes. Luisa, que ha tenido la desgracia de ser huérfana y ha sufrido de soledad y las penurias, lo mismo. La unión entre ambos ha dado el mejor de los frutos, una niña de ojos profundos, alegre, tranquila y sonriente. Han pensado para ella un nombre hermoso que encienda gozoso las mañanas: Mariluz.

Los días pasan con lentitud de nubes y las aceras se pueblan de ruiseñores, primavera en las ropas de estos árboles cercanos a una vega sembrada de tabaco y de maizales, mientras un padre duerme a su niña "con nanas de caballos,/con la salmodia triste del judío,/del converso que habita por su sangre" $(U O)$ bajo la mirada serena de una madre. Pero ha habido un alzamiento militar y el miedo es una sombra que anda por las calles, se agazapa en las esquinas y muerde a los que pasan. España está herida en sus cuatro costados. Es julio de nube y plomo, fin de mes en el piso apacible de la calle Carril del Picón. Tocan a la puerta. Es el vecino, un tipógrafo salmantino, un activista político de ultraderecha que viene a avisar a Agustín de que se esconda rápido, de que lo están buscando. Se llama Ramón Ruiz Alonso y pocos días después será quien denuncie y detenga a Federico García Lorca. Pero Agustín no quiere ocultarse. No debe temer un profesor que es reflector de conciencia comprometido con Granada y con sus gentes, un hombre que sólo ha trazado una senda de esfuerzos desde su pueblo burgalés, allá por Pedrosa del Príncipe, donde su padre es un humilde agricultor. Él se ha criado entre lagares y majuelos regados por el Odra y estrellas que dibujan un carro en la cumbre cercana del Cotorro del Aro. Su mujer le suplica que se marche hasta ver lo que sucede. Le hace caso, pero echa tanto de menos a esa niña que a principios de septiembre vuelve. Se repite que no existe delito en dar oportunidades a la gente que antes no las tuvo. Es una persona tan intachable en su conducta, tan honorable, que se ha olvidado del día de marzo en que unos militares borrachos intentaron llevarse por la fuerza a una adolescente de la Residencia de Señoritas a las once de la noche. Luisa lo impidió y él, como Director, al día siguiente denunció al líder de los canallas. Se llamaba José Valdés Guzmán y hace dos meses lo nombraron comandante de las fuerzas franquistas que han tomado la ciudad. Un loco, dicen. La sífilis y el alcoholismo lo están matando, cuentan otros, pero antes tiene que cumplir su misión de horror y de sangre. 
En los primeros días de septiembre se llevan a Agustín Escribano a la calle Duquesa, sede del Gobierno Civil. Nadie le ayuda, ni siquiera su beatísimo tío Víctor que afirma secamente que "él se lo ha buscado" ante la desolación de Luisa. El día doce, en el silencio de la madrugada, lo llevan a las tapias del Cementerio de San José y lo fusilan. Sangre. Sangre. Sangre. Es una venganza personal de Valdés que aprovecha las disputas intestinas de la Escuela Normal y la ambición de poder de los antagonistas de Agustín que son quienes lo denuncian. Se hace el silencio, un silencio muy negro, que cubre la estatura de una ausencia que oscurece la mañana y convierte en escarcha el calor de una caricia postrera: “Mariluz, pequeña, niña sin padre,/en qué lugar encontrarás sus manos,/en dónde su palabra y su sonrisa,/en qué lugar sus ojos apagados,/cegados por cemento y tierra roja" $(U O)$. Y la luna se esconde. Y llueve dulcemente la tristeza del agua cuando una niña de meses, en los brazos cansados de su madre, que es ya luto perpetuo y alta dignidad, va camino del destierro, a Palencia, donde no existen montañas y los chopos tienen una luz distinta: "Mi madre es una estatua/ sentada en la maleta,/ y un soldado me acuna/ con una canción triste./ Ha empezado el destierro/ hacia un futuro incierto./ Mi madre se ha olvidado/ de cantarme una nana" $(C G)$. Así se construye la historia. Y también la poesía.

\section{3.- Escribir en Granada ("Era un tiempo de canciones y trigo, /con Federico ausen- te como un muerto", UO)}

Una niña de cuatro años regresa a Granada. Es alta y delgada, de asombro fácil observando cada detalle, demorándose en cada esencia con la inocencia plena en su risa de ángel: "Mi ciudad era dorada/ con un fondo de nieve/ y un olor a frutales,/ linos y tabacos/y trigo en la pradera" (GM). Y juega veloz y corre y salta los charcos en un patio con bancos y niños de la guerra. No conoce bien los límites de la palabra padre. La mujer de negro la acompaña siempre, guía cada paso con austera angustia, el miedo detenido en su semblante grave. Si pasa algo, ¿quién protegerá su sueño? ("Pequeño niño, dulce asombro,/ palabra,/ estancia y primavera y abril en tu sonrisa./ Duermes y encierras el mundo/ en un fanal el cielo,/ y ríes, si despierto, juega el sol en tu párpado”, $U O$ ). La lucha sólo acaba de comenzar. Hay que prepararla para sobrevivir, mostrarle el mundo, abrirle un universo, posibilidades de supervivencia por si te pasa algo....

Y llega la música, las notas del solfeo, el violín antiguo, la disciplina del piano, los veranos en Madrid, en aquella residencia con pinos y leyendas. Así transcurren los días para la madre, con un estoicismo que murmura "hoy es ayer y ayer melancolía/ de lo que pudo ser y no haber sido" (CT). Porque Luisa está vigilada, esperan una falta, una mínima razón que propicie la expulsión y el desamparo, arruinar su nombre y su carrera, aquella que empezó en Madrid y que han intentado arrebatarle, como al marido que tanto amaba. Y Luisa calla y calla sin saber que aquella niña la contempla como espejo: "Mi madre era la fuerza sideral de los hondos/ caminos de la espiga alejada del agua./ Y es que yo la 
miraba desde el patio llovido,/ cuando la superficie de la tarde moría,/ y sabía que ella reposaba un momento/ y leía despacio a Miguel de Unamuno" (DUMS). La niña es lo primero y necesita un porvenir, acostumbrarla a defenderse en un mundo de injusticias, crueldad innecesaria y maldad en cada esquina: "Y el silencio se agranda en el silencio,/ y las conversaciones languidecen,/ y lloran las palabras y los lutos/ por Federico ausente como un muerto,/ por tantos muertos con el pecho herido/ en las lunas de agosto y de septiembre" (UO).

Avanza la posguerra y la chiquilla crece como un juncal gozoso en la ribera, ajena al mundo de desdicha para adultos que hablan bajito y se tragan las penas. Todo es descubrimiento para ella: la Huerta de San Vicente donde pasa los veranos con los primos de Federico, una noche de Reyes corriendo tras Melchor por la Gran Vía, aquella bicicleta, la yegua de Pedrosa en el septiembre de la llanura y la escuela de la Aneja, tan cerca de su madre. Dauro y Genil son sus referentes para transitar una época, "con mapas y lecciones/ en un palacio antiguo,/ el fragor de los trenes/ hacia el país del trigo,/ la lluvia sobre el mar/ y las arenas suaves" $(C G)$. Porque la niña viaja; lo primero ha sido comprarle un kilométrico para que pueda irse en aquellos vagones antiguos a Madrid y enlazar con pueblo de su padre en la Castilla verdadera.

Y la niña es lista y tiene preguntas sin respuesta. Y un día hurga en los cajones y desde este instante ya lo sabe, aunque nadie se lo ha dicho: "No comí pan de padre/ por causa de la guerra" $(C G)$. No hay conversación, sólo un "sí, hija”, un rayo que parte el corazón del tiempo y después un mutismo largo, la ratificación de la ignominia contra el hombre dulce de sonrisa clara que, antes de marcharse, ella intuye que dejó un beso en su almohada.

La muchacha avanza por los duros senderos, y ya es una joven linda que canta, va y viene, que ríe con los ojos de su padre, idéntico carácter de aborrecimiento a la injusticia. Tiene las manos grandes, el alma campesina y ama esta ciudad con entrañas de fruta porque sabe que aquí continúan las pisadas que persigue. Estudia Filosofía y Letras, Geografíay a la vez es maestra porque, aunque no lo intuye siquiera, ella tiene un destino: encender la casa con el nombre de su padre, tender puentes con un futuro que no llega y alzar la voz para contar la verdad de la injusticia, la ignominia cometida en nombre de la guerra: "En la colina roja de la Alhambra/ te cegaron los ojos,/ y yo sé que estás muerto / por fierros y fusiles, / pistolas asesinas/ para un tiro de gracia/ Aunque siempre te espero/ con la casa encendida/ por ver si me acaricias / con tu mano la frente" (GM). 


\section{4.- Mariluz Escribano, poeta del compromiso y la memoria ("Todo el mundo cono- ce/que heredé de mi padre una bandera", UO)}

Han pasado cincuenta años y 1989 ha tomado posesión del calendario. Luisa es desde hace un mes estrella blanca y vigilante, sal marina de un verano que principia. Este año viene vestido del gris de la nostalgia. En la altura de las rocas se observa una mujer imperturbable que mira la tormenta. A su alrededor se rompen las olas en mil pedazos de evocaciones y desdichas. Pero ya no tiene miedo, sólo una soledad profunda y la desolación de que todo se escribe en pasado: "Ahora tengo una mano de marfil/y otra de ausencia/y ejerzo de tristeza y de noviembre" (CT). La ilusión se ha quedado en los alamillos azules de la infancia, en la higuera de la Huerta, en las acequias con verdín que se rodean de hierbas olorosas y canciones de niña o en aquellos bosques de Ohio, donde "el ambiente es dorado,/ con una luz cambiante/ porque el verde se va de retirada,/ y el agua se desliza y burbujea/ por una piedra del color del cobre" (GM).

Porque yo sé, Mariluz, que hoy tú crees que todo está perdido. Las horas del reloj, la escritura que no acaba, los borradores con tachados, esos pactos que nunca te cumplieron. Comprendo desazones y amarguras, una vida que fue cuesta empinada, ciprés cementerial erguido y triste, tempestades incesantes, defensa de Granada con mil páginas de prensa ("como el que sabe, con demorada certidumbre,/que la ciudad es su casa,/ irremediablemente y para siempre", CT) y jóvenes en las aulas que pronuncian tu nombre embargados de fuego y construirán universos con monedillas de oro invisibles en sus aulas imitando tu ejemplo.

Por eso aguarda, ten paciencia, "porque la noche tiene una tristeza/que no cabe en la mano" (CT), pero tú tienes la fuerza de la sinceridad en tus labios y un misterio de laurel debajo de la frente. Aún queda una oportunidad, un guiño del azar, que es dueño de una carta, esa que nunca leíste y que ha de llegar cuando menos lo esperes para reconstruir ruinas, melodías de otro tiempo y verdades inmortales. Es rastrero silenciar a una mujer que es un pájaro sobrevolando acantilados con grietas imposibles de cerrar, los desfiladeros de la memoria fragmentada en mil pedazos. Que intenten que seas eco en el vacío de una ciudad afónica y perdida: "Mi ciudad marinera/ sin sol ni sombra,/ marinera a lo lejos,/ perdido el mar./ Yo navego entre brumas / de mi nostalgia,/ navegando, navego, / ¡barco a la mar!” (GM). Pero a la mujer valiente de las rocas, le quedan el tiempo la justicia. Aunque sea poética. 


\section{5.- Los encuentros necesarios ("Saliste de la niebla/ de aquel bosque encendido de noviembre", GM)}

Dos mil dos y un pájaro ultimísimo en la enramada desnuda, anunciando el otoño que ha llegado como señal cumplida cuando los pétalos del rosal de la parata primera ya son recuerdo. La mañana trae novedades presentidas mientras caen lentamente las flores del magnolio en el empedrado del jardín donde habita la memoria.

Lo has visto al salir, mientras acariciabas a Coco y te ibas al trabajo de labrar una escuela de discípulos entusiastas que te espera impaciente. Luego llegan las horas del despacho, ésas que tanto te aburren porque tu eres movimiento, arroyo desbordado, lumbre que abrasa la apatía de otros. Alguien toca a tu puerta, alguien llama en busca de consuelo, buscando explicarte, "el susto de la niebla/ que impedía acercarse/ a la canción del viento,/ al enhiesto rojizo de los árboles” (GM). Y tú lo has entendido, sabes la envergadura de lo que pasa, porque has aprendido a mirar a fuerza de golpes, de traiciones y mentiras: pero llega el momento de alzar un puente que sea futuro, esperanza presentida que llega temerosa y se sujeta al dintel. Sólo escuchas y observas porque ves el alma allá en lo hondo. Cuando los membrillos inunden el salón del olor del otoño, sabes que ha llegado el momento de modelar esta arcilla natural de barro rojo para hacer la efigie de tu propio rostro en otro que será continuación y testigo, canciones recordadas, poemas retomados, los libros publicados y la ilusión de que no todo está perdido. Desde este instante ya eres un espejo como tu madre donde se refleja mi fisonomía, la bondad que disipa la niebla cuando ya nada se ve, sólo se intuye, faro que evita los naufragios, serenidad inapelable de un hada madrina que se convierte en un bosque encantado con veredillas de luz que no se apagan. Has rescatado una niña, Mariluz. Y sabes, también, que la niña te ha rescatado a ti.

\section{6..- Conclusiones para empezar de nuevo un diálogo con una madre ("Cuando me vaya / habré perdido tantas cosas, / que creceré en trigal por no morirme", AM)}

Paseamos por la Huerta. Últimamente, Mariluz, siempre quieres ir a la Huerta, y no sé por qué, cobijarte en los celindos y hablar con el balcón de Federico en un dialogo de silencios y verdades compartidas. Y yo te acompaño, como siempre, porque ya no estás sola, nunca volverás a estar sola en la infinitud sideral del tiempo, mientras te leo en los ojos la angustia de tu padre, el amor a tu madre y a esa infancia que fue patria indiscutible, refugio de pobreza limpia, el reducto del violín y de la risa. Aquí se resume todo: naturaleza, infancia, melancolía, y amigos que se fueron progresivamente. Y memoria. Memoria. Memoria. Es un baúl de recuerdos azules y verdes y violetas que no se agota.

Pero ya lo escribes en pasado, y a mí me duele porque ahora sé que con tus dedos conjuras las tormentas, hablas y amanece en el limonero y "si vienes con un pájaro en el pecho, los cielos se abrirán para gozarlo” $(G M)$. Tienes la cabeza ágil, el recuerdo 
intacto y un mechón azul corona tu imagen de poeta inmensa que tiene en las nuevas generaciones a sus valedoras, a los que mejor la entienden, curiosa paradoja de quien habla de pasado pero es presente interminable. Ellos, los chicos que abarrotan esta Aula Magna, expectantes con tu visita de magia y de arco iris que es mayo presentido, son cómplices del secreto, saben que la emoción se escribe con palabras sencillas, irremediablemente precisas, que el artificio sin verdad es una pirueta para ocultar que detrás no hay aliento.

Han llegado los premios, al fin, esos que nunca esperaste pero que tanto merecías por ser distinta, irrepetible verdad firmemente dicha con voluntad de amparo de los que nunca pudieron expresarlo. Tu nombre está escrito en piedra, eres la voz del tiempo y estás cansada de tanto batallar, aunque luchas "en la densa tristeza/ de mis piernas inmóviles" (GM) porque te sabes querida y necesaria, el hombro perfecto donde reposan las zozobras, esa angustia de vivir que es cotidiana.

Pero te estás yendo lentamente con tu padre, con esa madre que fue tu hogar, como un río fresco que necesita confundirse en el mar y yo tengo miedo, te lo he dicho mientras miramos la difuminada nieve ultimísima desde esta habitación de hospital. Avisaste hace mucho: "Cuando surja la luz de primavera,/ y las rosas dibujen sonrisas de colores,/ escribiré una carta para cinco muchachos,/ contándoles lo mucho que gané con la vida" (CG). Entonces te supliqué que no te marcharas y tú te esperas con un sacrificio colosal y diario, con la generosidad perdurable de quien lo ha dado todo para que los demás no tengan que perder nada más. Hace un rato te he contado que los gorriones han hecho sus nidos, por estar cerca de ti, en el árbol de la entrada al sanatorio. Hacen vuelos rápidos con la comida para los polluelos en un griterío inmenso que oculta los ruidos de la calle. Pronto echarán a volar y serán libres, como tú anhelas. Sonríes en la paz de tu alma limpia y hay un lago de plata en tus labios, una ternura invariable cuando me dices aquello que necesito aprender, pero que nunca es suficiente, porque hace mucho frío ahí afuera, donde el abrigo de una madre no alcanza.

Sé que te vas en un rato, aunque no te lo he dicho, pero tal vez lo sepas. Me he agarrado a tu mano como siempre, como quien coge un salvavidas para no ahogarse, aunque es tarde ya. Queda la súplica: "Vuelve pronto, regresa,/ que ya viene el otoño/ en el viento amarillo de los prados, / y yo echo de menos tu sonrisa,/ las cosas que me cuentas, tus canciones,/ y ese dormir atento a mi llamada/ cuando te necesito/ en las noches oscuras" (GM). Pero no puede ser, tienes tareas postergadas, un futuro de reencuentros felices y fraternidad de amigos que se fueron antes (Eduardico, Tadea, Isabelita, Juan y tantos...) y que te esperaban, y yo lo entiendo.

Sé que no me pierdes de vista desde las altas cumbres donde nace la aurora y tu padre te besa la frente abrazado a tu madre y el dolor no te alcanza. Que me sigues susurrando al oído los nombres de las cosas, las canciones de siempre que atesoro y que sonríes con eterna paciencia, mínimamente confiada en que sea capaz de cruzar el laberinto y no me pierda; que tu alma me acuna con una inabarcable infinitud de ternura. Y tú también sabes que quedas resguardada, Mariluz, que yo te lo juré aquel junio de jazmines 
y almendros en flor: proteger tu memoria de "paloma blanca de tan alto vuelo,/ huésped fugaz del aire estremecido" ( $S A$ ) para que nunca se borre tu nombre de mujer de verso en pecho, de poeta de guardia, de patrimonio de todos. Por eso, porque "ahora es tiempo de paz./de paz y de memoria" ( $C G)$, yo te llamo a cada instante, para que tú me oigas y sepas que nada acaba, que cada segundo es un principio, una flor que se abre, un jilguero que despierta y dice tu nombre como una oración.

Lo has logrado, Mariluz Escribano, poeta, hermosa niña sin padre, hermana de la espiga, sobrina de la brisa, compatriota de los pájaros y amiga perpetua de los álamos que silban la canción del viento en la vega de Zujaira. Ahora eres libre y violeta y nosotros mantendremos tu legado de testigo de la Historia, esa ambición de concordia y entendimiento, de respeto y de justicia, de compromiso con las palabras verdad y amor. Y, aunque "la soledad me inunde de amarillos" $(C G)$ este corazón que es ya tu casa, sé que el vínculo es indestructible, que sigo andando tras tus pasos ya sin niebla, persiguiendo las huellas de tu estirpe con la réplica exacta de tus gestos anclada para siempre en la pupila. Y que estás viva, porque tú eres trigo que brota cada año, que se siembra y se recoge en un ciclo perpetuo, ahora que todo el mundo conoce que yo también heredé de mi madre una bandera.

NOTA: Todos los versos citados responden a poemas de Mariluz Escribano que se explican así: Sonetos del alba (SA), Desde un mar de silencio (DUMS), Canciones de la tarde (CT), Umbrales de otoño (UO), El corazón de la gacela (CG), Azul melancolía. Antología personal (AM) y Geografía de la memoria (GM). 


\section{Referencias bibliográficas}

-Escribano Pueo, M. (i993). Desde un mar de silencio. Granada: Cuadernos del Tamarit.

- Escribano Pueo, M. (1995). Canciones de la tarde (Prólogo de José Espada). Madrid: Torremozas.

- Escribano Pueo, M. (2005). Sonetos del alba (Prólogo de Gregorio Salvador [Real Academia Española] y Estudio Preliminar de Remedios Sánchez García). Granada: Dauro, $2^{\circ}$ ed.

- Escribano Pueo, M. (20I3). Umbrales de otoño (Estudio Preliminar de Remedios Sánchez). Madrid: Hiperión (Premio de la Crítica 2OI4).

- Escribano Pueo, M. (2015). El corazón de la gacela, Granada: Valparaíso.

- Escribano Pueo, M. (20i6). Azulmelancolía. Antología personal. Madrid: Visor.

-Escribano Pueo, M. (20I7). "Esbozo para una poética imposible" en La palabra silenciada: voces de mujer en la poesía española contemporánea (1950 - 20I5) / coord. por María Remedios Sánchez García, Manuel Gahete Jurado, Tirant Lo Blanch: Valencia, pp. 44I-446.

- Escribano Pueo, M. (2018). Geografía de la memoria. Valencia: Calambur. 